\title{
SIMULATION OF ONE-PHASE PARTIALLY SATURATED GROUNDWATER FLOW
}

\author{
H. M. KARKURI ${ }^{1}$, M. HASHEM ${ }^{2,{ }^{\star}}$ and M. T. SHAMAA ${ }^{3}$ \\ ${ }^{I}$ Civil Engineering Department, Higher Institute of Engineering, \\ Hoon, Libya \\ ${ }^{2}$ Civil Engineering Department, Faculty of Engineering, \\ Assiut University, Assiut, Egypt \\ ${ }^{3}$ Civil Engineering Department, Faculty of Engineering, \\ Al Mansoura University, Egypt \\ *Corresponding author: mhashem99@yahoo.com
}

(Received August 26, 2007 Accepted December 10, 2007)

The mathematical description of groundwater flow through a deformable porous medium has been obtained by combining Darcy's law with the mass conservation equations of both the groundwater and the soil mass. The partial differential equation governing the transient fluid flow with its appropriate initial and boundary conditions is the result. The numerical implementation of these differential equations for a rigid porous medium under partially saturated conditions has been achieved by converting them into integral equations by applying Galerkin's "weighted residual formulation" and Green's theorem. The finite element programs have been implemented in the FORTRAN "90" numerical environment. The numerically simulated one-dimensional compressible groundwater flows under saturated conditions were validated by comparing their results with analytical solutions. Satisfactory agreements were found between their results and the corresponding analytical solutions. For the partially saturated condition steady state and transient groundwater flow severe limitations in the formulation were encountered, in particular for the higher suction range in coarse granular materials.

KEYWORDS: Residual chlorine, Kinetic model, neural network.

\section{INTRODUCTION}

The integral equation for groundwater flow through multilayered porous media is obtained by multiplying the differential equation and boundary conditions by independent weight functions which are then integrated over their whole regions of definition. Both types of integrals are added together and demanding that their sum is zero [4]. Green's theorem is applied to minimize the highest derivatives of the weight functions. The numerical implementation is validated by comparing numerical simulations with basic analytical solutions.

The governing differential equation for groundwater flow under partially saturated conditions is based on the conservation of mass of the groundwater, leading to $[1,3]$ : 


$$
\begin{aligned}
& f K_{i j} \frac{\partial}{\partial x_{i}}\left(\frac{1}{\gamma^{w}} \frac{\partial P}{\partial x_{j}}+\delta_{j 2}\right)+\frac{C^{k} K_{i j}}{\gamma^{w}} \frac{\partial P}{\partial x_{j}} \frac{\partial P}{\partial x_{i}}+C^{k} \delta_{j 2} K_{i j} \frac{\partial P}{\partial x_{i}}+\frac{\beta^{w} f K_{i j}}{\gamma^{w}} \frac{\partial P}{\partial x_{j}} \frac{\partial P}{\partial x_{i}}+ \\
& +\beta^{w} \delta_{j 2} K_{i j} \frac{\partial P}{\partial x_{i}}-n S^{w} \beta^{w} \frac{\partial P}{\partial t}-n C^{s} \frac{\partial P}{\partial t}-S^{w} \delta_{i j} \frac{\partial \varepsilon_{i j}}{\partial t}=0
\end{aligned}
$$

in which $\mathrm{f}$ is the relative permeability, $\mathrm{k}_{\mathrm{ij}}$ is the soil coefficient of permeability in $\mathrm{m} / \mathrm{s}$, $\gamma^{\mathrm{w}}$ is the water volumetric weight in $\mathrm{N} / \mathrm{m} 3, p$ is the pore-water pressure in $\mathrm{N} / \mathrm{m}^{2}, \delta_{\mathrm{ij}}$ is the Kronecker delta, $\beta^{\mathrm{w}}$ is the water compressibility in $\mathrm{m}^{2} / \mathrm{N}, \mathrm{n}$ is the soil porosity, $\mathrm{S}^{\mathrm{w}}$ is the degree of saturation and

$$
C^{k}=C^{f} x C^{s}=\frac{d f}{d s^{w}} \frac{d s^{w}}{d p} \text {. Where } C^{f}=\frac{d f}{d s^{w}} \text { is the slope of the tangent of the }
$$

relationship between the relative permeability $f$ and the degree of saturation $S^{\mathrm{W}}$, and $C^{s}=\frac{d s^{w}}{d p}$ is the specific soil moisture capacity see e.g. Figure (1) and Figure (2).

The boundary conditions for groundwater flow are described by the following expressions. On the boundary $\Gamma^{\text {press }}$ the pressure $\mathrm{p}$ is prescribed:

$$
P=P
$$

in which - indicates that the corresponding quantity is prescribed. On the boundary $\Gamma^{w-f l u x}$ the flux q of groundwater is prescribed by:

$q=-\frac{k_{i j}}{\gamma^{w}}\left(\frac{\partial p}{\partial x_{i}}+\gamma^{w} \delta_{j 2}\right) n_{i}$

in which $\mathrm{n}_{\mathrm{i}}$ is the components of the normal vector of the boundary. The condition of the conservation of mass at interfaces between layer does not lead to any additional term in the integral equation. The resulting integral equation for the finite element analysis of partially saturated groundwater flow through a rigid porous medium is given by the following expression [5]:

$$
\begin{aligned}
& f_{k}^{u}=\sum_{\text {elements } \Omega_{e}} \int_{\Omega_{e}} \frac{\partial N_{k}}{\partial x_{i}} \frac{f k_{i j}}{\gamma^{w}} \frac{\partial N_{m}}{\partial x_{j}} d \Omega \hat{P}_{m}+\sum_{\text {elements } \Omega_{e}} \int_{\Omega_{e}} \frac{\partial N_{k}}{\partial x_{i}} f k_{i j} \delta_{j 2} d \Omega- \\
& -\sum_{\text {elements } \Omega_{e}} \int_{k} N_{k} \hat{P}_{r} \frac{\partial N_{k}}{\partial x_{i}} \frac{C^{k} k_{i j}}{\gamma^{w}} \frac{\partial N_{s}}{\partial x_{j}} \hat{P}_{s} d \Omega-\sum_{\text {elements } \Omega_{e}} \int_{k} N_{k} C^{k} \delta_{i 2} k_{i j} \frac{\partial N_{k}}{\partial x_{i}} d \Omega \hat{P}_{m}- \\
& -\sum_{\text {elements } \Omega_{e}} \int_{k} N_{k} \hat{P}_{r} \frac{\partial N_{k}}{\partial x_{i}} \frac{\beta^{w} f k_{i j}}{\gamma^{w}} \frac{\partial N_{s}}{\partial x_{j}} \hat{P}_{s} d \Omega-\sum_{\text {elements } \Omega_{e}} \int_{k} N_{k} \beta^{w} f \delta_{i 2} k_{i j} \frac{\partial N_{k}}{\partial x_{i}} d \Omega \hat{P}_{m}+ \\
& +\sum_{\text {elements } \Omega_{e}} \int_{k} N_{k} n s^{w} \beta^{w} N_{m} d \Omega \frac{\partial \hat{P}_{m}}{\partial t}+\sum_{\text {elements } \Omega_{e}} \int_{k} N_{k} n C^{s} N_{m} d \Omega \frac{\partial \hat{P}_{m}}{\partial t}- \\
& -\sum_{\substack{\text { boundary } \\
\text { elements }}} \int_{\Gamma_{e}^{\text {press }}} N_{k} n_{i} \frac{\partial k_{i j}}{\gamma^{w}} \frac{\partial N_{m}}{\partial x_{j}} d \Gamma \hat{P}_{m}+\sum_{\substack{\text { boundary } \\
\text { elements }}} \int_{\Gamma_{e}^{w-f l u x}} N_{k} q d \Gamma=0
\end{aligned}
$$


where $f_{k}^{u}$ in equation (4) is the unbalance or residual vector, which has as many components $\mathrm{k}$ as there are weight functions $\mathrm{N}_{\mathrm{k}}$, one for each node; it must be zero for a solution. The nodal quantity $\hat{P}_{m}$ is the nodal pore pressure for node $\mathrm{m}, \Omega_{e}$ is the volume of an element and $\Gamma_{e}$ is the surface of a boundary element. Equation (4) can be condensed to the following expression:

$f_{k}^{u}=P_{k m} \hat{P}_{m}+W_{k m} \frac{d \hat{P}_{m}}{d t}+R_{k}^{p}=0$

where $\mathrm{P}_{\mathrm{km}}$ is the global "Permeability matrix", $\mathrm{W}_{\mathrm{km}}$ is the global "Compressibility matrix" and $R_{k}^{p}$ is the global "Right-hand vector". The quadratic terms as given by third and fifth terms in equation (4) are not known. Their values will be estimated and updated through the iteration process.

\section{NUMERICAL IMPLEMENTATION}

The numerical implementation for the ten terms of groundwater flow as expressed by equation (4) was performed by using a finite element computer model known as "GRWUNSAT.F90". For partially saturated conditions the degree of saturation $\mathrm{S}^{\mathrm{w}}$, the reduction factor (relative permeability) f, the slope of the specific soil moisture capacity $\mathrm{C}^{\mathrm{s}}$ and the slope of the relationship between the reduction factor $\mathrm{f}$ and the effective permeability $\Theta, \mathrm{C}^{\mathrm{f}}$ are all functions of pore- water pressure head $\Psi=-\frac{P}{\gamma^{w}}$.

Since the degree of saturation $\mathrm{S}^{\mathrm{w}}$, the relative permeability $f$, the specific soil moisture capacity $C^{\mathrm{s}}$, the slope of the relationship between the relative permeability $\Theta$ and pore water suction $\Psi, \mathrm{C}^{\mathrm{f}}$ and the two quadratic terms appearing on the right-hand side of equation (4) are all functions of the pore-water pressure head $\Psi$, their values can be calculated using an iterative procedure.

\section{The Iterative Procedure for Reduction of Unbalance}

The actual form of the unbalance vector $f_{k}^{u}$ as given by equation (4) can be expressed symbolically in the following form of equation (5) for groundwater flow [2]. It should be noted, that for the calculation of the unbalance vector $f_{k}^{u}$ the matrices need only to be calculated at element level at most. From equations (5) it is clear, that the required solution is obtained when the unbalance would be equal to zero. This occurs if the assumed pore-water pressures coincide with the required solution. However in general non-zero unbalance $f_{k}^{u}$ will occur, which will depend on the previous estimates of the pore-water pressure field. The unbalance vector consists of as many components as degrees of "free" freedoms of the element mesh.

Defining $\hat{P}_{k}$ as the nodal pore-water pressure of node $\mathrm{k}$ leads to the same number of components of the unbalance vector as $f_{k}^{u}$ the number of unknown free 
nodal pressures $\hat{P}_{k}$. Consequently the required solution must be obtained by means of an iterative procedure in which the nodal pore-water pressure has to be corrected in such a way to make the unbalance approach zero. The Newton-Raphson iteration procedure has been implemented in program "GRWUNSAT.F90" to calculate the initial and transient states of groundwater flow under saturated and partially saturated conditions

\section{DESCRIPTION OF THE PROBLEM ANALYSED}

The groundwater flow program is validated by simulating the compressible groundwater flow through a saturated sandy soil column with a height of $2 \mathrm{~m}$ and a width of $0.02 \mathrm{~m}$ as illustrated in Figure (3) and by comparing the results with known analytical solutions. The loading system in this analysis is the pore-water pressure distributions $\mathrm{p}$ from the base of the mesh, and distributed with time in the vertical direction. The vertical groundwater flow velocity, $\mathrm{v}=10^{-5} \mathrm{~m} / \mathrm{sec}$. or specific discharge $\mathrm{q}=3.5 \times 10^{-6} \mathrm{~m} / \mathrm{sec}$. for soil porosity $\mathrm{n}=0.35$. In the Finite Element program, Equation (4) for full saturation can be written in the following ordinary differential form:

$P\{\hat{P}\}+W\left\{\frac{d \hat{p}}{d t}\right\}=\left\{-R^{p}\right\}$

where $\mathrm{P}$ is the global "Permeability matrix", $\mathrm{W}$ is the global "Compressibility matrix" and $\mathrm{R}^{\mathrm{p}}$ is the contribution from the boundary sections considered in the calculation. In order to integrate this ordinary differential equation in the time domain the "CrankNicolson" method involving time step $\Delta \mathrm{t}$ is applied [3].

\section{NUMERICAL SIMULATIONS}

The groundwater flow under partially saturated conditions is simulated for continuous desaturation. Desaturation of soil's voids has a complex effect upon its ability to transport moisture. The process of desaturation evacuates the larger interstices first which reduces the pore volume available for transmission. Moreover, the remaining flow pathways must track around the periphery of the pore chambers thereby increasing their tortuosity. The combined effect is to significantly reduce the permeability of the soil as desaturation proceeds. This desaturation effect can be incorporated by the application of a coefficient $f$ of relative permeability to the saturated permeability, $\mathrm{k}^{\mathrm{s}}$.

Under the conditions of the partially saturated flow, the resulting flux is strictly a two phase phenomenon involving flow of pore-water and water vapour through the air phase. However, if the pore air is assumed to be everywhere atmospheric and the contribution by vapor flow can be assumed to be relatively small then the problem can be reduced to one of single flow namely flow of pore fluid. Nevertheless, the presence of air voids complicates the description of flow in the 
liquid phase since both soil suction and permeability are related to the degree of porewater saturation. In this paper, the problem of groundwater flow has been treated as a single phase flow.

To simulate the one-dimensional partially saturated groundwater flow, the case of gradual desaturation of the soil column from the bottom is discussed. The boundary conditions involve zero prescribed pore-water flux at the top of mesh and ramp type prescribed pore-water pressure from $p=19620 \mathrm{~N} / \mathrm{m}^{2}$ to $p=-19620 \mathrm{~N} / \mathrm{m}^{2}$ at the bottom for Ramp time $=10^{6} \mathrm{sec}$. and time step DTIM $=10^{3} \mathrm{sec}$. The numerically calculated pore water pressure distributions as a result of this analysis are illustrated in Figure (5) for times, namely $\mathrm{t}=0, \mathrm{t}=2.5 \times 10^{5}, \mathrm{t}=5 \times 10^{5}, \mathrm{t}=7.5 \times 10^{5}$ and $\mathrm{t}=8 \times$ $10^{5} \mathrm{sec}$.

The calculated degree of saturations as a function of depth for the same time intervals are illustrated in Figure (5). This figure indicates that the soil is fully saturated throughout the soil column at time $t=0 \mathrm{sec}$. (initial state conditions). Figure (5) shows that at zero time the pore-water pressure distribution is linear and corresponding to the initial hydrostatic case, in which the hydraulic head is equal to 2 $\mathrm{m}$ of water at the bottom and equal to zero $\mathrm{m}$ at the top. At the subsequent time, namely $\mathrm{t}=2.5 \times 10^{5} \mathrm{sec}$. The pore water pressure distribution is still practically linear and hydrostatic with a pore pressure of $-9810 \mathrm{~N} / \mathrm{m} 2$ at the bottom (see figure (4) but partial saturation starts to occur near the top (see figure (5). The top $0.3 \mathrm{~m}$ of the soil column starts to become partially saturated with a minimum value of degree of saturation $S^{\mathrm{w}}=0.951$.

A non-linear negative pore-water pressure distribution occurs at half of ramp time, namely $\mathrm{t}=5 \times 10^{5} \mathrm{sec}$. The pressure at the bottom of the mesh is equal to the prescribed value which is equal to zero while at the top it is equal to $-16297 \mathrm{~N} / \mathrm{m}^{2}$. In case of a linear distribution it would have been equal to $-19620 \mathrm{~N} / \mathrm{m}^{2}$. This delayed response of the pore pressure is due to the severely reduced permeability which resists the extraction of the pore water from the upper partially saturated part at the applied rate of pressure change at the bottom. The soil is only fully saturated up to $0.8 \mathrm{~m}$ above the bottom. At higher levels the saturation decreases drastically to a value of $S^{\mathrm{w}}$ $=0.312$ at the top.

At time, $t=7.5 \times 10^{5} \mathrm{sec}$. the prescribed pore pressure at the bottom boundary is $-9810 \mathrm{~N} / \mathrm{m}^{2}$. At the top the pressure decreases only to a value of $-17664 \mathrm{~N} / \mathrm{m}^{2}$ rather than that of $-29430 \mathrm{~N} / \mathrm{m}^{2}$ according to a linear hydrostatic distribution. At the bottom a degree of saturation $\mathrm{S}^{\mathrm{w}}=0.937$ is reached and the saturation decreases to a value of $\mathrm{S}^{\mathrm{w}}$ $=0.281$ at the top. This indicates that the whole soil column is under partially saturated conditions. The response at $\mathrm{t}=0.8 \times 10^{5} \mathrm{sec}$. shows similar distributions with slightly larger suction and a further increased desaturation.

The calculation failed by a division by zero at around $t=9.55 \times 10^{5} \mathrm{sec}$. This failure can be attributed to the limitation of the mathematical formulation adapted from the literature for handling the partially saturated conditions. Close inspection of figure (3) shows that at the last two time intervals, namely $t=7.5 \times 10^{5}$ and $t=8 \times$ $10^{5} \mathrm{sec}$. the saturation values at the top of soil column are approaching the saturation value at retention, namely $S^{r}=0.25$ of the soil under consideration. The corresponding 
hydrostatic heads at these times are only -1.8 and -1.817 m respectively which should not be severe compared to the high suction values encountered in real situations.

\section{ANALYSIS OF TRANSIENT FLOW}

\section{Zero Prescribed Pore-water Flux at Top}

To investigate the ability of the formulation and numerical implementation to simulate transient phenomena during and following a ramp type of change, the previously prescribed maximum pore-pressure in ramp loading at the bottom of the soil column was reduced from $\mathrm{p}=19620 \mathrm{~N} / \mathrm{m}^{2}$ to $\mathrm{p}=4905 \mathrm{~N} / \mathrm{m}^{2}$. While at the top zero pore-water flux was prescribed.

The degree of saturation as a function of depth for the same time intervals indicates that the soil is practically fully saturated throughout the soil column at the first three time intervals, namely, $\mathrm{t}=0, \mathrm{t}=2.5 \times 10^{5}$ and $\mathrm{t}=5 \times 10^{5} \mathrm{sec}$. At time $\mathrm{t}=$ $7.5 \times 10^{5} \mathrm{sec}$. the top $0.4 \mathrm{~m}$ of the soil column starts to become partially saturated with a minimum value of $S^{\mathrm{w}}=0.8485$ at the top of the soil column. At the time equal to the ramp time, namely $\mathrm{t}=10^{6} \mathrm{sec}$. the soil is saturated up to about $1.2 \mathrm{~m}$ above the bottom. At higher levels the saturation decreases drastically to a value of $S^{w}=0.4025$ at the top. At five times the ramp time, namely $\mathrm{t}=5 \times 10^{6} \mathrm{sec}$. the soil is still fully saturated up to about $1.2 \mathrm{~m}$ above the bottom. At the top the saturation decreases to a value of $\mathrm{S}^{\mathrm{w}}=0.3944$. At ten times the ramp time, namely, $\mathrm{t}=10 \times 10^{6} \mathrm{sec}$. the saturation has not changed anymore.

This value of final saturation at the top of mesh in fact is corresponding to about $20 \%$ of the total saturation between $S^{w}=1.0$ and $S^{w}=0.25$. The corresponding minimum value of the relative permeability $f$ as a result of this analysis was found to be equal to 0.009 . The corresponding pore-water flux distribution at time intervals $\mathrm{t}=$ $0, \mathrm{t}=2.5 \times 10^{5}, \mathrm{t}=5 \times 10^{5}, \mathrm{t}=7.5 \times 10^{5}, \mathrm{t}=10^{6}, \mathrm{t}=5 \times 10^{6}$ and $\mathrm{t}=10 \times 10^{6} \mathrm{sec}$. indicates that at the early times, namely, $\mathrm{t}=0, \mathrm{t}=2.5 \times 10^{5}$ and $\mathrm{t}=5 \times 10^{5} \mathrm{sec}$., when the soil is practically saturated, the calculated pore-water flux at the bottom at these times is also practically equal to zero. As the time goes by, namely, at $t=7.5 \times 10^{5}$ and $t=10^{6} \mathrm{sec}$. the soil starts to de-saturate at the top. In such case the flux at the bottom must be larger than the zero value in order to withdraw the amount of water already existing in the larger pores between the state of full saturation and the new saturation values at the top of $\mathrm{S}^{\mathrm{w}}=0.8485$ and $\mathrm{S}^{\mathrm{w}}=0.4025$ at these times respectively. The corresponding effective saturations are about $\Theta=0.8$ and $\Theta=0.2$ respectively.

At five and ten times of the ramp time, namely, $t=5 \times 10^{6}$ and $t=10 \times 10^{6}$ sec. the pore water flux distributions were found to have practically returned back to a zero value as expected. This indicates that the soil has reached its equilibrium state at which no further water is withdrawn. This analysis seems to be satisfactory.

\section{Non-zero Prescribed Pore-water Flux at Top}

The same analysis was repeated for a boundary condition with a prescribed pore-water influx of $\mathrm{q}=5 \times 10^{-9} \mathrm{~m} / \mathrm{sec}$. at the top of the soil column. This value was maintained throughout the calculation time. The corresponding pore-water flux distribution at time intervals $\mathrm{t}=0, \mathrm{t}=2.5 \times 10^{5}, \mathrm{t}=5 \times 10^{5}, \mathrm{t}=7.5 \times 10^{5}, \mathrm{t}=10^{6}, \mathrm{t}=5 \times 10^{6}$ and $\mathrm{t}=10^{7}$ see. indicates that at early times, namely $t=2.5 \times 10^{5}$ and $t=5 \times 10^{5} \mathrm{sec}$. when the 
soil is also practically saturated the calculated pore-water flux at the bottom at these times are $\mathrm{q}=5 \times 10^{-9}$ and $\mathrm{q}=5.5 \times 10^{-9} \mathrm{~m} / \mathrm{sec}$. respectively which is practically equal to the prescribed value at the top. As the time goes by, namely, at $\mathrm{t}=7.5 \times 10^{5}$ and $\mathrm{t}=$ $10^{6} \mathrm{sec}$. the soil starts to desaturate at the top. At these times the flux at the bottom will be larger than the prescribed value in order to withdraw the amount of water between the state of full saturation and the new saturation values at the top of $S^{\mathrm{w}}=0.8485$ and $\mathrm{S}^{\mathrm{w}}=0.4025$ at these time respectively. The maximum flux at the bottom at time $\mathrm{t}=$ $10^{6} \mathrm{sec}$. is practically equal to that in the previous case with zero prescribed flux at the top.

At five and ten times of the ramp time, namely, $\mathrm{t}=5 \times 10^{6}$ and $\mathrm{t}=10 \times 10^{6}$ see. The pore water flux distributions were found equal to the prescribed value of $q=5$ $\mathrm{x} 10^{-9} \mathrm{~m} / \mathrm{sec}$. at the top and equal to $\mathrm{q}=4.268 \times 10^{-11}$ at the bottom for both time intervals. This flux value at the bottom is in fact much smaller than steady state value of $\mathrm{q}=5 \times 10^{-9} \mathrm{~m} / \mathrm{sec}$. Considering the calculated difference in flux at top and bottom and the conservation of mass of pore-water, basic to the formulation it must be expected that near the top of the soil column during the period following the ramp time the saturation must increase.

To investigate this further, consider the difference in time between the ramp time of $10^{6} \mathrm{sec}$. and the time of the last time interval $10^{7} \mathrm{sec}$. which is equal to $9 \times 10^{6}$ sec. The volume of water passing through the area per $\mathrm{m}^{2}$ due to the prescribed porewater flux can be expressed in terms of height of a water column $\mathrm{h}=\mathrm{q} \cdot \mathrm{t}=5 \times 10^{-9} \times 9$ $\times 10^{6}=45 \times 10^{-3} \mathrm{~m}$. the analysis indicates that at the last time interval the saturation value at the top of the soil column is equal to $\mathrm{S}^{\mathrm{w}}=0.3944$. Considering the soil porosity $n=0.35$ the real height of the resaturating water column in terms of $\mathrm{H}$ follows from:

$$
H=\frac{h}{\left(1-S^{w}\right) x n}=0.21 \mathrm{~m}
$$

This indicates that about $21 \mathrm{~cm}$ of the soil column at the top would be completely replenished and would become fully saturated if the mass of pore-water had been conserved. In fact, this has not occurred. It can be concluded that the numerical analysis through its iterative procedure is not handling the calculation of the pore-water flux properly under partially saturated conditions if the pore-water flux is prescribed at the boundary.

\section{STEADY STATE FLOW}

To investigate this limitation of not accounting for the prescribed pore-water flux at the top further numerical pore-water flux calculations for steady state pore-water flow were performed using the Newton-Raphson (N-R) iteration procedure. The calculations were started at a fully saturated hydrostatic state. Starting from this initial state both the pore pressure at the bottom of the mesh and the pore-water flux at the top of the mesh were changed step wise to reach the envisaged steady state in a chosen number of increments. For each increment a Newton-Raphson iteration was performed. The pore pressure at the bottom of the mesh at the investigated steady state were the same as considered in the transient case, namely, $\mathrm{P}=19620, \mathrm{P}=15941$, $\mathrm{P}=12262, \mathrm{P}=8583$ and $\mathrm{P}=4905 \mathrm{~N} / \mathrm{m}^{2}$. 
In this procedure, at the boundary with prescribed pressure at the bottom of the mesh the difference in pressure between the initial hydrostatic pressure distribution and the envisaged steady state pressure as mentioned above is divided into an equal number of increments. The prescribed steady state pore-water flux at the top of the mesh is divided into the same number of flux increments. For every increment of pressure and flux the N-R-iteration procedure is applied to arrive at a better estimate of the pore-water pressure and flux.

The analysis of combined pore-water pressure distributions for the five steady state cases are indicated clearly that the calculated flux distribution deviates more severely from the prescribed steady state value of $\mathrm{q}=5 \times 10^{-9} \mathrm{~m} / \mathrm{sec}$. as the desaturation increases. A possibly acceptable limit case is found for the case with prescribed pressure $\mathrm{P}=12262 \mathrm{~N} / \mathrm{m}^{2}$ at the bottom of the mesh which is corresponding to the first flux distribution. In this case, the deviation from the prescribed flux is about $98.7 \%$. In this case the effective saturation at the ground surface is about $\Theta=$ 0.996. From this it can be concluded, that the applied numerical model is not able to simulate the partially saturated flow for the case of prescribed pore-water flux at the boundary for $\Theta<0.996$. This is similar to the limitation observed for the transient analysis.

\section{CONCLUDING REMARKS}

The applied common mathematical formulation for one-phase partially saturated groundwater flow is found to have severe limitations in the relation between the saturation and the pore suction. In particular, the limitation to desaturate below the retention value seems to be fundamental.

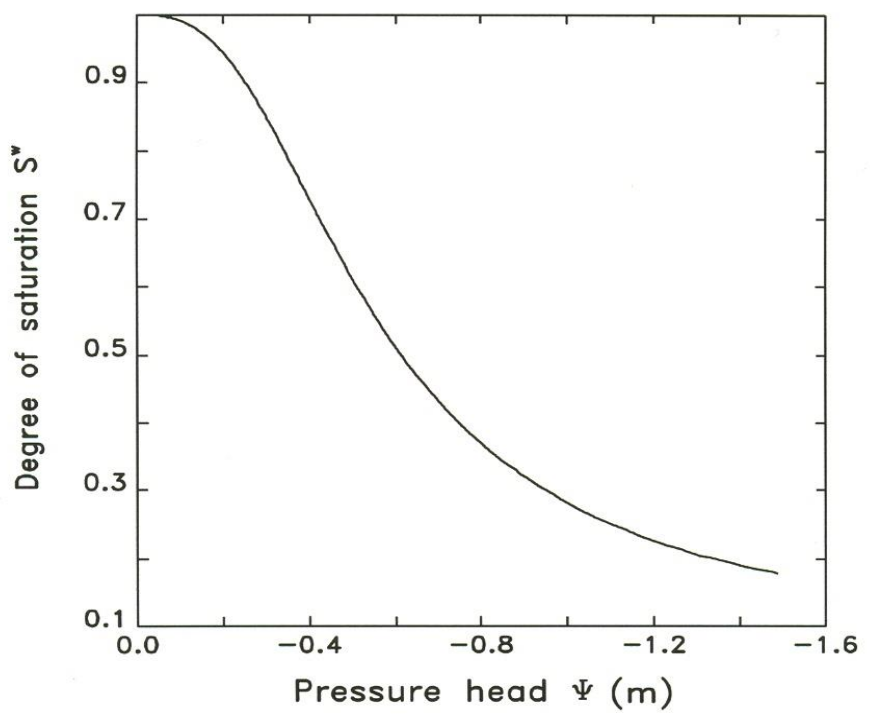

Figure (1) Relationship between the pressure head 'P, and the degree of saturation $\mathrm{S}^{\mathrm{W}}$, of sandy soil 


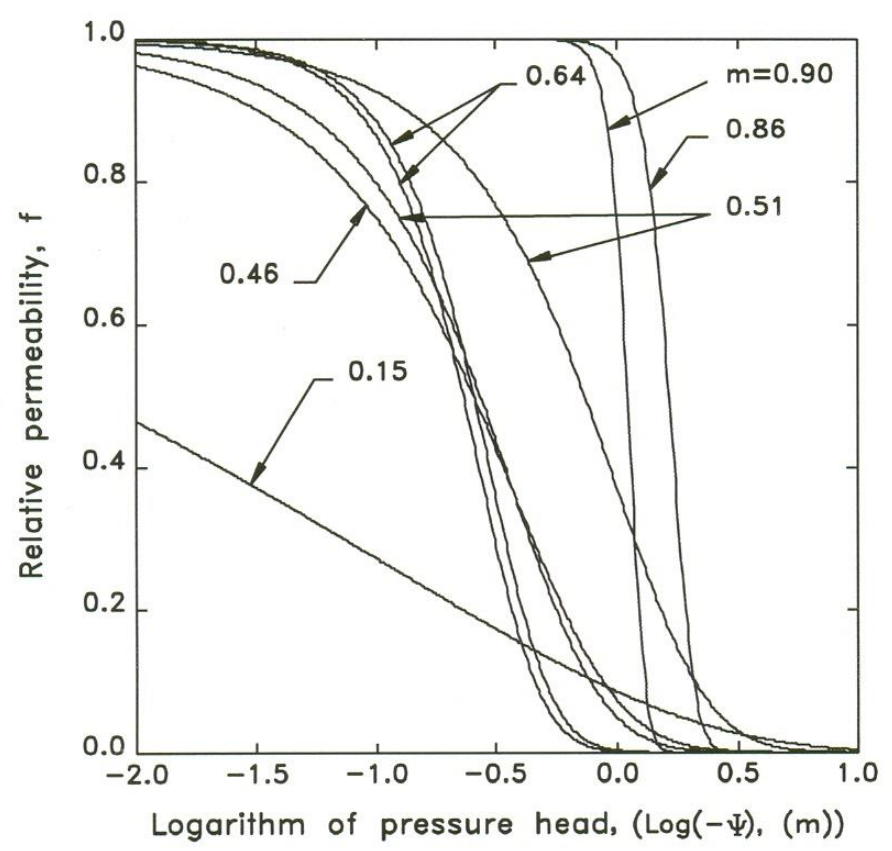

Figure (2) Relationships between the relative permeability $f$ and the pressure head



Figure (3) uniform soil column mesh of $2.0 \mathrm{~m}$ deep divided into 100 elements. 


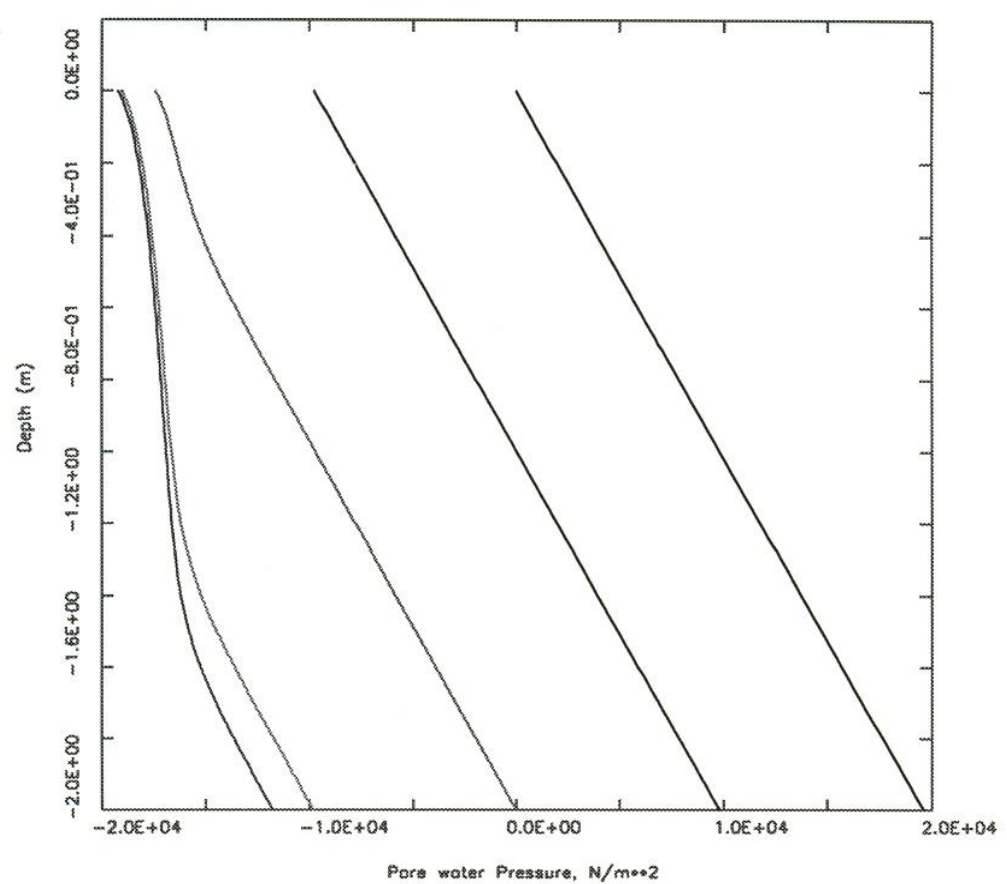

Figure (4) Numerical pore-water pressure distributions at $\mathrm{t}=0, \mathrm{t}=2.5 \mathrm{X} 10^{5}, \mathrm{t}=5 \mathrm{X}$ $10^{5}, \mathrm{t}=7.5 \times 10^{5}$ and $\mathrm{t}=8 \times 10^{5} \mathrm{sec}$.

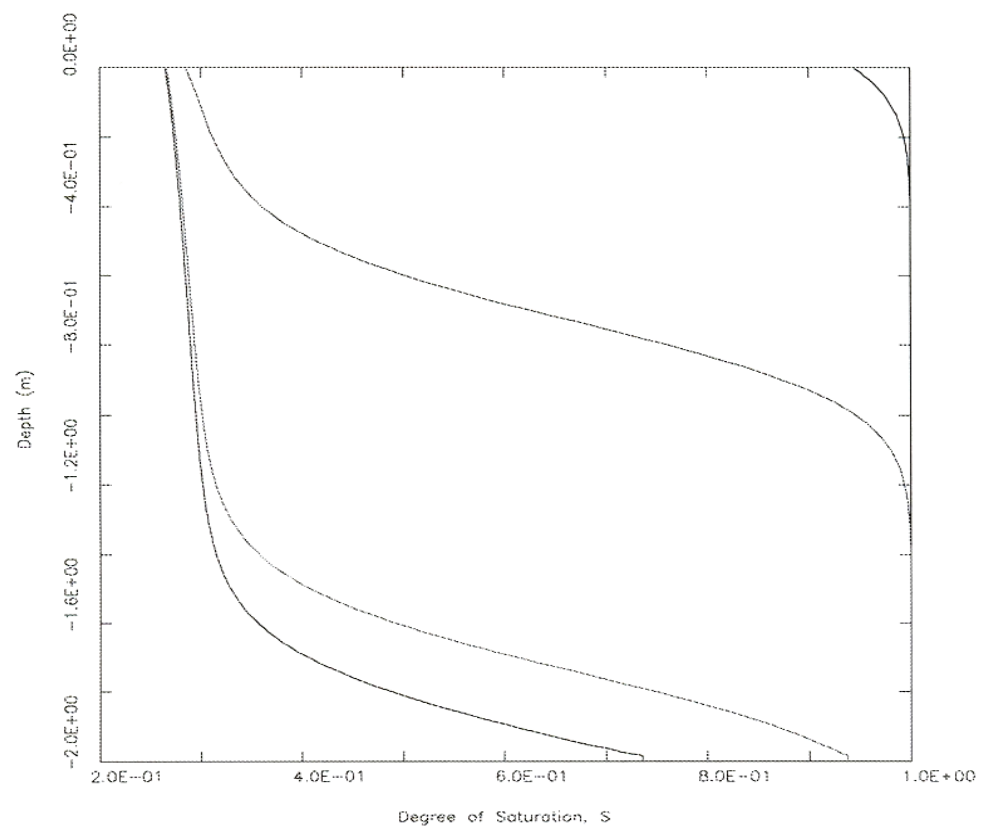

Figure (5) The relationship between the degree of saturation $\mathrm{S}^{\mathrm{W}}$ and the depth of soil column at $\mathrm{t}=\mathrm{O}, \mathrm{t}=2.5 \times 10^{5}, \mathrm{t}=5 \times 10^{5}, \mathrm{t}=7.5 \times 10^{5}$ and $\mathrm{t}=8 \times 10^{5} \mathrm{sec}$. 
It can be concluded that the developed numerical model is capable of simulating the partially saturated flow for the case of prescribed pore-water flux at the boundary, namely:

- If the prescribed boundary flux is zero then the effective saturation $\Theta$ must be larger than zero thus $\Theta>0$ to avoid division by zero. Reasonable simulations have been obtained for $\Theta \geq 0.2$.

- If the prescribed boundary flux is non-zero then the effective saturation e must be larger than about $\Theta>0.996$.

Practically full saturation can be simulated also. For lower saturation the Newton-Raphson iteration will not converge.

\section{REFERENCES}

1. Bear, J., and A. Verruijt. "Modeling Groundwater Flow and Pollution.". D. Reidel Publishing Company. Dordrecht, Holaland (1992).

2. Karkuri, H. M. "Groundwater Mechanics and Pollution Transport.".A PhD Thesis Submettited to The Unversity of Manchester Institute of Science and Technology(UMIST) (1998).

3. Smith, I. M., and D. V. Griffiths. "Programming The Finite Element Method. $2^{\text {th }}$ Edition."John Wiley \& Sons. New York (1992)

4. Van Genuchten, M. T. "A Closed-form Equation for Predicting the Hydraulic Conductivity of Unsaturated Soils.”. Soil Sci. Soc. Am. J., 44, 892-898 (1980).

5. Zienkiewicz, O. C., and R. L. Taylor. "The Finite Element Method. $4^{\text {th }}$ Edition. Vol. 1." McGraw-Hill Book Company, London (1994).

\section{تمثيل سريان المياه الجوفية فى حالة التثبع الجزئي}

الوصف أو التمثيل الرياضي لسريان المياه الجوفية فى التربة يتم الحصول عليه من تكامل قانون دارسي

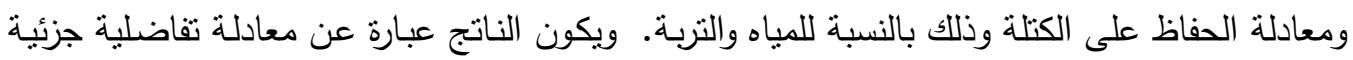
يمكن حلها بعدة طرق. فى هذا البحث تم استخدام طريقة العناصر المحددة لجالركن (Garlerkin) ونظرية قرين (Green theorem) كوسائل رقمية لحل معادلة السريان للمياه الجوفية فى حالة التشبع الجزئي. وقد تم فى هذا البحث إثبات أن الحل العددي (بالطرق العددية) ممكنا لهذه المعادلة وذلك رفئل بمقارنة النتائج بنتائج الحل الرياضي التحليلي الصحيح ووجد أن هناك توافق فى النتائج بين الحلين. 